\title{
Management of open fractures of the lower limb during the COVID-19 pandemic: are the standards of treatment being maintained? A study from a major trauma centre in England
}

\author{
Rajan Choudhary ${ }^{1}$, Madhumita Gupta ${ }^{2 *}$, Shahidul Huq ${ }^{2}$, Wareth Maamoun ${ }^{2}$
}

\begin{abstract}
${ }^{1}$ Department of Trauma and Orthopaedics, ${ }^{2}$ Department of Plastic Surgery, Royal Stoke University Hospital, Newcastle Road, Stoke on Trent, United Kingdom
\end{abstract}

Received: 26 July 2021

Revised: 10 August 2021

Accepted: 11 August 2021

*Correspondence:

Dr. Madhumita Gupta,

E-mail: docmadhu82@gmail.com

Copyright: (c) the author(s), publisher and licensee Medip Academy. This is an open-access article distributed under the terms of the Creative Commons Attribution Non-Commercial License, which permits unrestricted non-commercial use, distribution, and reproduction in any medium, provided the original work is properly cited.

\begin{abstract}
Background: Coronavirus disease 2019 (COVID 19) has created an immense strain on the NHS. During the height of the pandemic, trauma services were affected by redeployment, reduced theatre capacity and staff illness, and COVID BOAST guidelines were introduced.

Methods: This retrospective study aimed to evaluate the standards of management of open fractures of the lower limb at a Major Trauma Centre in the United Kingdom during the COVID-19 pandemic and compare the same with the prepandemic period. Patient demographics, mechanism of injury, timing and mechanism of initial debridement and definitive soft tissue and skeletal fixation were noted. Outcomes including duration of hospital stay, 30 day and 1 year mortality were also assessed.

Results: There was an overall $21 \%$ reduction in admissions with open lower limb fractures during the pandemic period with a $48 \%$ reduction during the first lockdown. There was a significant reduction in time taken from Emergency Department presentation to first debridement as well as a notable increase in operating outside of regular theatre hours. There was little difference in operative technique used for skeletal or soft tissue management at initial and definitive surgery, though fewer cases were performed as a two stage procedure. There was no difference in amputation rate in the two years. Length of stay was reduced from 21 days to 17, and 30 day mortality remained the same.

Conclusions: Our study shows this Major Trauma Centre was able to provide a trauma service in accordance to the BOAST4 guidelines despite the increased pressures of the COVID-19 pandemic.
\end{abstract}

Keywords: Open fracture lower limb, COVID-19, BOAST guidelines

\section{INTRODUCTION}

Coronavirus disease 2019 (COVID 19) has created a huge strain on the National Health Service of United Kingdom. At its peak during the second wave, 81,526 patients tested positive for COVID-19 in the UK on a single day, with 39,249 admitted, 4,077 intubated and ventilated, and the maximal death rate peaking at 1359 a day. ${ }^{1}$
In an effort to control the spread of the SARS-CoV-2 virus, the first lockdown was initiated on 23 March 2020 until 10 May 2020, followed by a second lockdown on 5 November. ${ }^{2}$ Along with other public health measures, this was successful in reducing the infection rate of the virus amongst the general population, in turn achieving the primary aim of reducing hospital admission and preventing the health service from being overwhelmed by excessive patient load. Despite this, provision of medical 
and surgical care was impacted during the pandemic, including trauma management.

Open fractures are managed at major trauma centres in the United Kingdom, as per the BOAST4 guidelines. ${ }^{3}$ To manage the anticipated increase in admission of medical COVID patients, as well as reduce inpatient stay and operative requirements for orthopaedic patients, all nonurgent elective orthopaedic surgery were postponed, and special COVID-19 BOAST guidelines introduced for management of trauma patients during these unprecedented times. ${ }^{4}$ This prioritised admission for patients who could not be managed non-operatively, favoured single stage procedures, and early amputation in cases where limb salvage was questionable and necessitated multiple operations.

Unfortunately, clinical pressures on medical wards and intensive care units resulted in re-deployment of anaesthetic and nursing staff to manage critically unwell COVID patients. Increases in ITU and medical ward requirements, as well as record numbers of simultaneous staff leave, due to COVID-19 infection and self-isolation, together resulted in decreases in theatre capacity for all surgical specialties and affected the volume of trauma patients that could be processed. This was further compounded by new COVID protocols, including the necessitation of COVID status prior to theatre, at a time when widespread PCR testing was not established, recovering all patients in theatre, and cycling the theatre air for a minimum of 20 minutes between cases. The focus on COVID prevention came at the expense of available theatre time and placed a strain on the combined surgical services at our major trauma centre.

The aim of this study was to review the management of patients with open lower limb fractures admitted to a Level 1 Major Trauma Centre in the West Midlands region of the UK, and compare the time taken from admission to first debridement and definitive skeletal and soft tissue cover during the COVID-19 pandemic in 2020 and nonpandemic functioning in 2019 and determine if the COVID-19 pandemic affected the orthoplastics service provided at our major trauma centre.

\section{METHODS}

This was a retrospective study performed in a single Level 1 Major Trauma Centre in the West Midlands, UK. Inclusion criteria were all patients admitted for open lower limb fractures between 01 March to 31 December 2020 (case group); these dates were chosen as the starting month of the UK lockdown to the end of the 2020 year. The control group was matched by dates, 01 March to 31 December 2019. Patients with open phalangeal fractures were excluded.

Data on patients with open fractures was obtained from the clinical coding team, and further data was obtained from the hospital Electronic Patient Records system (iPortal, Bluespier), clinic letters and patient discharge letters.

Data parameters included age, gender, time and date of admission, mechanism of injury, fracture location, time, and date of first debridement, definitive skeletal fixation and soft tissue coverage, method of skeletal and soft tissue management. If definitive fixation was achieved at first debridement, the same technique was recorded for both the initial debridement and for the definitive fixation.

Patients with multiple open fractures were treated as independent cases. Patients who were discharged with temporary skeletal fixation and re-admitted at a later date for definitive fixation were treated as a single case requiring two stage procedure.

Anatomical area of injury was categorised into femoral, knee, tibia, tibia-fibula, ankle, and foot. Mechanism of injury was categorised into fall at ground level, fall from height, road traffic accident, crush injury, sports injury, assault, and unknown.

Time from admission to debridement was categorised to $<24 \mathrm{hrs}, 24-36 \mathrm{hrs}$ and $>36 \mathrm{hrs}$. Time from first debridement to definitive fixation was categorised into $<72 \mathrm{hrs}, 72 \mathrm{hrs}-7$ days and $>7$ days. Cases that underwent first debridement between 2nd April and 25th June 2020 were categorised as 24-hour COVID theatres, between 2 nd April and 25th June 2019 as Control theatres, and the remainder categorised as normal theatres.

Patients who received their initial debridement at another trauma centre were included for analysis of surgical technique, but excluded from analysis of time to debridement, definitive skeletal fixation, and soft tissue coverage. Patients who died prior to their first debridement were included for analysis of demographics and mechanism of injury but excluded from all other analysis.

Statistical analysis on time to initial debridement, definitive skeletal fixation, soft tissue coverage and duration of stay differentiated by year was carried out with the Mann-Whitney U test. The non-parametric status of data collected was determined by Shapiro-Wilk normalcy test. All statistical analysis was carried out on $\mathrm{R}$ version 4.0.4 (2021-02-15). The level of significance was determined at a $\mathrm{p}<0.05$.

\section{RESULTS}

\section{Patient demographics}

We identified 191 open fractures in 178 individual patients ( 107 cases in 2019,84 cases in 2020). 6 patients were repatriated to our trauma centre following initial debridement and skeletal stabilisation at another site.

There was little difference in average age at presentation in 2020, 48.9 years compared to 50.4 in 2019 ( $\mathrm{t}$ test 
$\mathrm{p}=0.636$ ), and a change in patient gender distribution, with a significantly greater number of male patients presenting with injuries (2019 -male 57\%, female 43\%, 2020 - male $64 \%$, female $36 \%$ ) (Table 1 ).

Table 1: Patient demographics.

\begin{tabular}{|c|c|c|c|c|}
\hline \multirow{2}{*}{$\begin{array}{l}\text { Mechanism of } \\
\text { injury }\end{array}$} & \multicolumn{2}{|c|}{$\begin{array}{l}2019 \\
(n=107)\end{array}$} & \multicolumn{2}{|c|}{$\begin{array}{l}2020 \\
(n=84)\end{array}$} \\
\hline & $\mathbf{N}$ & $\%$ & $\mathbf{N}$ & $\%$ \\
\hline RTC & 48 & 45 & 32 & 38 \\
\hline Fall ground & 23 & 21 & 11 & 13 \\
\hline Fall from height & 17 & 16 & 25 & 30 \\
\hline Assault & 4 & 4 & 1 & 1 \\
\hline $\begin{array}{l}\text { Crush and fall } \\
\text { from height }\end{array}$ & 3 & 3 & 0 & 0 \\
\hline Unwitnessed & 3 & 3 & 1 & 1 \\
\hline Sports & 2 & 2 & 3 & 4 \\
\hline Unknown & 2 & 2 & 0 & 0 \\
\hline $\begin{array}{l}\text { Fall unknown } \\
\text { height }\end{array}$ & 2 & 2 & 3 & 4 \\
\hline Crush & 2 & 2 & 4 & 5 \\
\hline $\begin{array}{l}\text { Sports injury from } \\
\text { height }\end{array}$ & 1 & 1 & 3 & 4 \\
\hline Workplace injury & 0 & 0 & 1 & 1 \\
\hline \multicolumn{5}{|c|}{ Location of fracture } \\
\hline Ankle & 33 & 31 & 20 & 24 \\
\hline Tibia & 28 & 26 & 26 & 31 \\
\hline Tibia/Fibula & 20 & 19 & 19 & 23 \\
\hline Femoral & 16 & 15 & 10 & 12 \\
\hline Patella & 5 & 5 & 2 & 2 \\
\hline $\begin{array}{l}\text { Traumatic } \\
\text { Amputation }\end{array}$ & 2 & 2 & 2 & 2 \\
\hline Foot & 2 & 2 & 5 & 6 \\
\hline Fibula & 1 & 1 & 0 & 0 \\
\hline
\end{tabular}

During the period of first lockdown, between 25 March 2020 and 1 June 2020, there were only 18 patients admitted with open fractures. This was just over half of the admissions during the same period in 2019, 35 patients. The length of stay in hospital was not statistically significant between 2019 (21 days) and 2020 (17 days, $\mathrm{p}=0.4084$ )

Three patients had a 30-day mortality (average 8 days), with 10 suffering a 1-year mortality (average 77 days) in 2019. Only two patients admitted in 2020 suffered a 30day mortality, and a third patient died at 75 days. It is not possible to determine a 1-year mortality for the 2020 patient population at the time of writing. One patient died prior to first debridement and was excluded from further analysis.

There was a decrease in patients admitted as a result of road traffic accidents (48 versus 32) and fall at ground level (23 versus 11), with an increase in falls from height, notably from ladders and stepladders (17 versus 25$)$. The distribution of injury location did not differ considerably between 2019 and 2020 for tibial fractures (48 versus 45) or femoral fractures (16 versus 10), with a slight decrease in ankle fractures between the two years (33 versus 20).

\section{Timeline of operative management}

In 2019 it took on average 1308 minutes ( $21 \mathrm{hrs} 48 \mathrm{~min}$ ) for a patient to reach theatre for first debridement after presentation to the Emergency Department (ED). There was a statistically significant $47 \%$ decrease in average time to reach theatre in 2020 to 709 minutes $(11 \mathrm{hrs} 49 \mathrm{~min}$, Mann Whitney U p=0.01763) (Table 2).

The mean time for a patient to achieve skeletal fixation following first debridement in 2019 was 8 days 17 hours, which reduced to 4 days and 4 hours in 2020 (Mann Whitney $\mathrm{U}, \mathrm{p}=0.7999)$. The mean time to soft tissue coverage in 2019 was 9 days 8 hours, which also reduced to 3 days 12 hours in 2020 (Mann Whitney $\mathrm{U}, \mathrm{p}=0.3657$ ). Despite significant reductions in mean times, neither was statistically significant.

Table 2 Timeline of operative management.

\begin{tabular}{|lllll|}
\hline $\begin{array}{l}\text { Time from injury } \\
\text { to first } \\
\text { debridement }\end{array}$ & $\begin{array}{l}\text { 2019 cohort } \\
(\mathbf{n = 1 0 4})\end{array}$ & $\begin{array}{l}\text { 2020 cohort } \\
(\mathbf{n = 8 0})\end{array}$ \\
\hline <24 hrs & 88 & 85 & $\mathbf{N}$ & \% \\
\hline $\mathbf{2 4 - 3 6 h r s ~}$ & 8 & 8 & 0 & 0 \\
\hline$>\mathbf{3 6}$ hrs & 8 & 8 & 4 & 5 \\
\hline P value & $\mathrm{p}=0.01763$ \\
\hline $\begin{array}{l}\text { Time from first } \\
\text { debridement to: }\end{array}$ & Definitive skeletal fixation \\
\hline 72hrs & 58 & 56 & 49 & 61 \\
\hline 72hrs - 7 days & 28 & 27 & 15 & 19 \\
\hline 7 Days + & 18 & 17 & 16 & 20 \\
\hline p value & $\mathrm{p}=0.7999$ & & \\
\hline
\end{tabular}

\begin{tabular}{|c|c|c|c|c|}
\hline \multirow{2}{*}{$\begin{array}{l}\text { Time from first } \\
\text { debridement to: } \\
72 \mathrm{hrs}\end{array}$} & \multicolumn{4}{|c|}{ Definitive soft tissue fixation } \\
\hline & 53 & 51 & 47 & 59 \\
\hline $72 \mathrm{hrs}$ - 7 days & 32 & 31 & 22 & 28 \\
\hline 7 Days + & 19 & 18 & 11 & 14 \\
\hline $\mathrm{p}$ value & \multicolumn{4}{|c|}{$\mathrm{p}=0.3657$} \\
\hline \multicolumn{5}{|c|}{ Out of hours operating at initial debridement } \\
\hline Normal Hours & 88 & 85 & 54 & 68 \\
\hline Out of Hours & 16 & 15 & 26 & 33 \\
\hline \multicolumn{5}{|c|}{ Skeletal fixation managed in } \\
\hline Two Stage & 57 & 55 & 44 & 55 \\
\hline One Stage & 47 & 45 & 36 & 45 \\
\hline \multicolumn{5}{|c|}{ Soft tissue coverage managed in } \\
\hline Two Stage & 65 & 63 & 48 & 60 \\
\hline One Stage & 39 & 38 & 32 & 40 \\
\hline
\end{tabular}

6 patients were excluded from this data set as their initial operation was performed at a separate centre prior to repatriation to our MTC. 1 patient was excluded as they died prior to first debridement. 
After presentation, $85 \%(\mathrm{n}=88)$ of our patients achieved first debridement within 24 hours in 2019, whilst $95 \%$ $(n=76)$ achieved it in 2020. There was a similar increase in patients achieving definitive skeletal and soft tissue management within 72 hours of first debridement. Skeletal fixation was achieved within 72 hours in $61 \%(n=49)$ of cases in 2020, compared to $56 \%(n=58)$ in 2019. Definitive soft tissue coverage also had an increase to $59 \%(n=47)$ from $51 \%(n=53)$.

There was a notable increase in out of hours operating in 2020 at initial debridement. Patients were operated on outside of regular theatre hours, from $8 \mathrm{am}$ to $8 \mathrm{pm}$, in $15 \%$ of cases in $2019(n=16)$, and 33\% of cases in $2020(n=26)$.

Skeletal fixation was surgically managed in two stages in $55 \%$ of cases in $2019(n=57)$, and $2020(n=44)$. Soft tissue cases were managed as part of a two-stage procedure in $63 \%$ of cases in $2019(n=65)$ and $60 \%$ in $2020(n=48)$.

\section{4-hour COVID trauma theatres}

18 patients were admitted between the dates of 2 nd April and 25th June 2020 during 24-hour COVID Trauma theatres, with 35 patients admitted between 2nd April and 25th June 2019 as a control group. Mean time to initial debridement took 17 hours 17 minutes in the control group, and 9 hours 52 minutes in the 24-hour group (Mann Whitney $U, p=0.1972$ ).

Mean time for a patient to achieve skeletal fixation following first debridement in the control group was 18 days 2 hours, which reduced to 1 day 23 hours in the 24hour Theatre group (Mann Whitney U, p=0.7999). The mean time to soft tissue coverage in the control group was 20 days 23 hours, which also reduced to 1 day 20 hours in the 24-hour Theatre group (Mann Whitney U, $\mathrm{p}=0.009631$ ).

$100 \%$ of the patients admitted in 2020 received their initial debridement within 24 hours of presentation to ED, with only $83 \%$ of those in the control group achieving this. Definitive skeletal fixation was achieved within 72 hours of initial debridement in $67 \%$ of the 2020 patient cohort, and only $46 \%$ of the 2019 control cohort. Similarly definitive soft tissue coverage after initial debridement was achieved within 72 hours in $78 \%$ of patients in the 2020 cohort, compared to $57 \%$ in the 2019 control cohort.

\section{Operative techniques}

There was little difference in technique used for skeletal fixation at first debridement between the two cohorts of patients (Table 3).

Fixation was managed by external fixation in $58 \%$ of cases in $2019,57 \%$ in $2020(n=48, n=62)$, temporary casting in $8 \%$ and $11 \%$ of cases $(n=9, n=9)$, treatment with ORIF from $7 \%$ to $10 \%(n=7, n=8)$. There was a small decrease in patients managed with intramedullary nailing from $18 \%$ to $17 \%(\mathrm{n}=19, \mathrm{n}=14)$.

Table 3: Operative techniques.

\begin{tabular}{|c|c|c|c|c|}
\hline \multirow{2}{*}{$\begin{array}{l}\text { Initial skeletal } \\
\text { fixation type }\end{array}$} & \multirow[b]{2}{*}{$\mathbf{N}$} & \multirow[b]{2}{*}{$\%$} & \multirow[b]{2}{*}{$\mathbf{N}$} & \multirow[b]{2}{*}{$\%$} \\
\hline & & & & \\
\hline External fixation & 62 & 58 & 48 & 57 \\
\hline Intramedullary nail & 19 & 18 & 14 & 17 \\
\hline $\begin{array}{l}\text { Backslab and } \\
\text { immobilisation }\end{array}$ & 9 & 8 & 9 & 11 \\
\hline ORIF & 7 & 7 & 8 & 10 \\
\hline None & 6 & 6 & 1 & 1 \\
\hline Wire fixation & 2 & 2 & 0 & 0 \\
\hline Amputation & 1 & 1 & 2 & 2 \\
\hline Internal fixation & 0 & 0 & 2 & 2 \\
\hline \multicolumn{5}{|c|}{ Initial soft tissue fixation type } \\
\hline Direct closure & 55 & 52 & 45 & 54 \\
\hline $\begin{array}{l}\text { Vacuum assisted } \\
\text { closure }\end{array}$ & 34 & 32 & 25 & 30 \\
\hline Conventional dressing & 9 & 8 & 5 & 6 \\
\hline NA & 4 & 4 & 4 & 5 \\
\hline $\begin{array}{l}\text { Split thickness skin } \\
\text { graft }\end{array}$ & 2 & 2 & 2 & 2 \\
\hline None & 1 & 1 & 0 & 0 \\
\hline $\begin{array}{l}\text { Full thickness skin } \\
\text { graft }\end{array}$ & 1 & 1 & 0 & 0 \\
\hline Local flap & 0 & 0 & 2 & 2 \\
\hline Free flap & 0 & 0 & 1 & 1 \\
\hline \multicolumn{5}{|c|}{ Definitive skeletal fixation type } \\
\hline Intramedullary nail & 43 & 41 & 31 & 37 \\
\hline ORIF & 33 & 31 & 26 & 31 \\
\hline External fixation & 14 & 13 & 13 & 15 \\
\hline Amputation & 6 & 6 & 7 & 8 \\
\hline $\begin{array}{l}\text { Backslab and } \\
\text { immobilisation }\end{array}$ & 4 & 4 & 6 & 7 \\
\hline None & 3 & 3 & 0 & 0 \\
\hline $\begin{array}{l}\text { Distal femoral } \\
\text { replacement }\end{array}$ & 1 & 1 & 0 & 0 \\
\hline Wire fixation & 1 & 1 & 0 & 0 \\
\hline Ex Fix + IM Nail & 1 & 1 & 0 & 0 \\
\hline Ex-Fix + ORIF & & 0 & 1 & 1 \\
\hline \multicolumn{5}{|c|}{ Definitive soft tissue fixation type } \\
\hline Direct closure & 71 & 67 & 61 & 73 \\
\hline Free flap & 15 & 14 & 8 & 10 \\
\hline $\begin{array}{l}\text { Split thickness skin } \\
\text { graft }\end{array}$ & 10 & 9 & 7 & 8 \\
\hline Local flap & 6 & 6 & 7 & 8 \\
\hline NA & 3 & 3 & 0 & 0 \\
\hline $\begin{array}{l}\text { Full thickness skin } \\
\text { graft }\end{array}$ & 1 & 1 & 0 & 0 \\
\hline $\begin{array}{l}\text { Vacuum assisted } \\
\text { closure }\end{array}$ & 0 & 0 & 1 & 1 \\
\hline
\end{tabular}

There was also little difference in technique for definitive skeletal fixation between 2019 and 2020. Intramedullary nails accounted for $41 \%$ and $37 \%$ of cases $(n=43, n=31)$, 
ORIF $31 \%$ and $31 \%(n=33, n=26)$, external fixation $13 \%$ and $15 \%(n=14, n=13)$, amputation $6 \%$ and $8 \%(n=6, n=7)$ of cases.

Initial soft tissue fixation was managed by direct closure in $52 \%(n=55)$ of cases in 2019 , compared to $54 \%(n=45)$ in 2020. Vacuum assisted closure (VAC) was used in $32 \%$ and $30 \% \quad(n=34, n=25)$, managed with conventional dressings in $8 \%$ and $6 \%(n=9, n=5)$. There was little difference in technique for definitive soft tissue fixation between the two years, with most cases managed by direct closure, $67 \%$ in $2019,73 \%$ in $2020(n=71, n=61)$. Free flaps were used in $14 \%$ and $10 \%$ of cases respectively $(n=15, n=8)$, split thickness grafts in $10 \%$ and $8 \%$ of cases $(\mathrm{n}=10, \mathrm{n}=7)$, and local flaps in $6 \%$ and $8 \%$ of cases $(n=6$, $\mathrm{n}=7)$.

\section{DISCUSSION}

We compared our findings to similar studies looking at management of lower limb fractures in the UK and worldwide during the COVID pandemic. Three studies were identified, all published in 2020; Campbell et al (Royal London Hospital, East London), Gupta et al (Government Medical College, Chandigarh) and Berner et al (a multicentre study comparing results from 15 centres across 9 countries). ${ }^{5-7}$

Our study compares patients admitted over a 305-day period in 2020 to a similar period in 2019 , significantly more than the 48-day period seen in the Campbell study, 5 months in the Berner multicentre study, and the 118 days in the Gupta study, though unlike the Berner study we only reviewed patients in a single centre.

There was a $21 \%$ decrease in number of patients admitted under our Orthopaedics team with open fractures between 2019 and 2020. Comparing the period of first lockdown in 2020 to an equivalent period in 2019 (23rd March to 1st June), there was a drastic $66 \%$ decrease in open fracture presentations. This is comparable across the studies comparing 2020 and 2019 data, with an $18 \%$ reduction in the London cohort and $42 \%$ in Chandigarh.

This can be taken in context with figures for patients presenting to Emergency Departments. NHS England reported 16.2 million people visiting ED in 2019 between January and December, with only 12.9 million reported during the same time period in 2020 , a $20.5 \%$ decrease. ${ }^{8}$ There was a similar reduction of patients admitted from ED as an inpatient, from 6.53 million to 5.48 million $(16.1 \%)$.

We can also demonstrate similarities in injury presentation and mechanism of injury across all cohorts, with the majority of fractures involving tibia/fibula, caused by road traffic accidents. These findings did not change between 2019 and 2020 despite national lockdowns in the UK and other represented countries. In our data the percentage of RTC induced injuries decreased (45\% to $38 \%)$, and this was compensated with nearly a two-fold increase in injuries sustained by falls from heights (16\% to $30 \%)$. These injuries include falls downstairs and ladders and are likely a consequence of people staying indoors during lockdown and work from home situations, or participating in home improvement do-it-yourself projects to occupy time.

Unlike the other cohorts we appear to have an older patient population, with mean age of 48.9 years (London 37 years, Chandigarh 34.8 years, Multicohort 43.6 years). This appears to reflect the Median and mean age of local population covered by these major trauma centres; Staffordshire having an average age of 41.9 years, East London and Essex 33.9 and 41.2 years respectively, and Chandigarh a youthful 28.5 years..$^{9,10}$

Our Major Trauma Centre was able to significantly improve on the time taken for our open fracture patients to reach theatre for first debridement of their injuries by $47 \%$, and improve the percentage that were achieving this within 24 hours of presentation to ED. All studies showed similar improvements in time to first debridement, though not to such a high degree (14\% and 23\% improvement for high and low energy cases in London respectively, $21 \%$ improvement in Chandigarh).

These results may partially be explained by the increased out of hours operating during 2020; from the 2020 cohort $33 \%$ were operated out of hours, more than double the $15 \%$ of patients operated out of hours in 2019. Though out of hours operating is discouraged under normal circumstances following evidence from NCEPOD audits and the BOAST guidance, 24 hour COVID theatres were set up between 2 Apr 2020 and 25 June 2020, in an effort to provide a major trauma service despite reductions in available theatres and redeployment of theatre staff to ICU and COVID surge roles. ${ }^{3,4}$

In fact, our data does show that our cohort had significantly improved adherence to BOAST guidelines during these 24-hour COVID trauma theatres, achieving $100 \%$ of first debridement within 24 hours of admission. The 24-hour theatres were only temporary and implemented at a time when the infectivity and mortality of SARS-CoV-2 was not known, and so emergency measures were implemented to manage trauma patients quickly and reduce duration of stay. During the second wave in November 24-hour trauma theatres were not re-implemented.

Whilst there was no statistically significant improvement in time taken for patients to have definitive skeletal and soft tissue fixation, there was a small improvement in percentage of patients that achieved this within 72 hours of first surgical debridement, though this still falls below BOAST guideline recommendations. ${ }^{4}$ The London and Chandigarh trauma centres reported greater improvements in their cohorts achieving definitive fixation within 72 hours, and this is an area we should aim to improve on in the future. 


\section{BOAST guidelines}

The COVID BOAST guidelines emphasise use of single stage procedures where possible, with the aim of preventing repeated theatre admissions and minimise duration of inpatient stay. In cases where limb salvage had an uncertain outcome necessitating multiple operations and prolonged inpatient stay, consideration for early amputation was advised.

Looking at our data, the number of patients requiring one stage vs two stage fixation for their definitive fracture and soft tissue management did not change significantly between 2019 and 2020. There also did not appear to be a significant difference in method used for skeletal and soft tissue management between 2019 and 2020, both on initial debridement and the definitive operation. This shows our operative management for lower limb fractures was not affected by COVID.

Unfortunately, the other studies do not show separate data on skeletal and soft tissue fixation at initial debridement and definitive surgery. The Gupta cohort show an increase in external fixator application use in 2020 (71\% from 51\%) with subsequent reduction in use of plating and nailing, 6 whereas the London cohort shows an increase in use of direct closure for soft tissue management ( $83 \%$ versus $73 \%$ ) with a decrease in use of free flaps (6\% versus $14 \%)$, local flaps and split skin grafts.

All studies show a similar rate of amputations, and amputation rate does not appear to increase in 2020, suggesting the BOAST guidelines recommendations on early amputations are either not necessary, were not required due to reduced incidence of such injuries or were not followed by the trauma centres.

\section{Interpretation}

From the data we collected at our Major Trauma Centre we can demonstrate that our centre was able to maintain the same degree of compliance with BOAST guidelines on management of open lower limb fractures during the COVID-19 pandemic as it had in 2019 pre-pandemic, and in some cases exceeded our pre-pandemic capabilities. ${ }^{4}$

This is likely due to the reduction in patients presenting with open fractures as a result of strict lockdown rules, in turn reducing the number of road traffic accidents that were the main cause of open lower limb fractures in 2019. Whilst the reduction in operating capacity due to staff redeployment, sickness and reduced available theatres is likely to have had a negative impact, our major trauma centre was still able to manage the patient workload presented to it.

This appears to be comparable to the other studies published at time of writing comparing their management of lower limb fractures before and during the COVID-19 pandemic. The presentation of trauma arriving at our major trauma centre, including demographics, mechanism of injury, fracture pattern and management of fractures appear to correlate well with the other studies.

Despite BOAST COVID guidelines suggesting a change in management of open lower limb fractures may be required to reduce operative load and discharge patients early, we did not find any significant change in practice when managing these cases pre-pandemic and during the pandemic, with regards to initial and definitive fixation of skeletal and soft tissue injury. We also found there to be little need for early amputation in complex fracture patterns, and our amputation rate between the two time periods remained relatively unchanged.

\section{CONCLUSION}

Despite the significant strain on the healthcare system the world over during the COVID-19 pandemic, our Major Trauma Centre has been able to sustain the same acceptable standard of care with respect to the management of patients with open lower limb fractures when compared to the pre-pandemic period. This is similar to the conclusion reached in other similar studies worldwide. The increased efficiency of out of hours trauma theatres have helped in achieving this in our case. It can hence be concluded that with adherence to standard surgical COVID-19 precautions and routine use of personal protective equipment, it would be possible to follow standard pre-COVID guidance and expect similar results in the management of these patients during any subsequent waves of the pandemic.

\section{Funding: No funding sources}

Conflict of interest: None declared

Ethical approval: The study was approved by the institutional ethics committee

\section{REFERENCES}

1. Cases in the UK. Coronavirus in the UK. Available at: https://coronavirus.data.gov.uk/details/cases. Accessed on $1^{\text {st }}$ May, 2021.

2. COVID-19 Response - Spring 2021 (Summary) GOV.UK. Available at: https://www.gov.uk/ government/publicat ions/covid-19-response-spring2021/covid-19-response-spring-2021-

summary\#roadmap-out-of-lockdown.Accessed on $10^{\text {th }}$ May, 2021.

3. BOAST - Open Fractures. Available at: https://www.boa.ac.u k/resources/boast-4-pdf.html. Accessed on $10^{\text {th }}$ May, 2021.

4. BOAST - Management of patients with urgent orthopaedic conditions and trauma during the coronavirus pandemic (Archived). Available at: https://www.boa.ac.uk/resources/covid-19-boastscombined1.html. Accessed on $10^{\text {th }}$ May, 2021.

5. Campbell E, Zahoor U, Payne A, Popova D, Welman T, Pahal GS, et al. The COVID-19 Pandemic: The effect on open lower limb fractures in a London 
major trauma centre - a plastic surgery perspective. Injury. 2021;52(3):402-6.

6. Gupta R, Singhal A, Kapoor A, Dhillon M, Masih GD. Effect of COVID-19 on surgical management of open fractures and infection rates: A tertiary care experience in Indian set-up. J Clin Orthop Trauma. 2021;12(1):16-21.

7. Berner JE, Chan JK, Gardiner MD, Rakhorst H, Ortega-Briones A, Nanchahal J, et al. RSTN COVID - INTELLECT Collaborative. Standards for treatment of open lower limb fractures maintained in spite of the COVID-19 pandemic: Results from an international, multi-centric, retrospective cohort study. J Plast Reconstr Aesthet Surg. 2021;74(7):1633-701.

8. Statistics. A\&E Attendances and Emergency Admissions 2020-21. Available at: https://www. england.nhs.uk/statistics/statistical-work-areas/ae- waiting-times-and-activity/ae-attendances-andemergency-admissions-2020-21/. Accessed on $10^{\text {th }}$ May, 2021.

9. Office for National Statistics. 2011 Census: Aggregate Data. 2020.

10. Census of India Website: Office of the Registrar General \& Census Commissioner, India. Available at: https://censusindia.gov.in/2011census/ population_enumeration.html. Accessed on $10^{\text {th }}$ May, 2021.

Cite this article as: Choudhary R, Gupta M, Huq S, Maamoun W. Management of open fractures of the lower limb during the COVID-19 pandemic: are the standards of treatment being maintained? A study from a major trauma centre in England. Int J Res Orthop 2021;7:894-900. 